\title{
The Effect of Using Naphthalene and Local Soil with Concrete Mixture on Thermal Conductivity, Case of Mafraq City - Jordan
}

\author{
Hussain H. Alzoubi ${ }^{*}$, Duha J. Al-Olaimat ${ }^{1}$ \\ 1 College of Architecture and Design, Jordan University of Science and Technology, Irbid 22110, Jordan \\ * Corresponding author's e-mail: alzoubih@umich.edu
}

\begin{abstract}
This study explores the effect of direct incorporation of different ratios of naphthalene with soil into the concrete used in Mafraq-Jordan on the thermal conductivity of concrete mixtures. The methodology involved testing 72 concrete cube samples. The basic samples were prepared only from a mixture of water, silica sand, and cement without additives. The additives of local soil and naphthalene of different ratios: $2.5 \%, 5 \%, 7 \%, 10 \%$ and $15 \%$, were added to the tested samples. The samples were classified into two groups in terms of size and dimensions; 36 cubes with $5 \times 5 \times 5 \mathrm{~cm}$ were tested only for thermal conductivity, and 36 cubes with $3 \times 3 \times 3 \mathrm{~cm}$ were tested for compressive strength and thermal conductivity. All samples were tested after 28 days of casting, according to the concrete standards. The results show that adding naphthalene and soil to the cementitious mixtures substantially decreases the thermal conductivity of concrete elements. A reasonable reduction in thermal conductivity was achieved compared with the basic case samples. However, the compressive strength of samples remained within the acceptable values from the stand point of structural engineering. This enhancement in the thermal properties of concrete can be applied in building systems as concrete blocks used in internal and external walls.
\end{abstract}

Keywords: naphthalene, thermal conductivity, compressive strength, silica

\section{INTRODUCTION}

The local energy production in Jordan is a little part of energy requirements in 2016; it only accounts for $5 \%$ of the total energy requirements in the kingdom, as indicated in Figure 1. This is a burden and negatively affects the growing Jordanian economy (Jordanian Ministry of Energy and Mineral Resources, 2017).

There are several factors affecting the energy usage in buildings which can be categorized into two main groups: First, the optical and thermal properties of the construction materials; second, the climatic conditions and the nature of the built environment (Shariah et al., 1997). The most important factor is the thermal properties of building materials. Passive design strategy is one way of minimizing the thermal conductivity and eventually reducing the heat loss in buildings. This study suggests adding material particles with low thermal conductivity, Kvalue, to the cementitious building elements.
These particles are called phase change materials (PCMs) (Alva et al., 2017).

In general, PCMs are classified into three major groups; organic compounds, inorganic compounds, and inorganic eutectics (Sharma, 2013), see Figure 2.

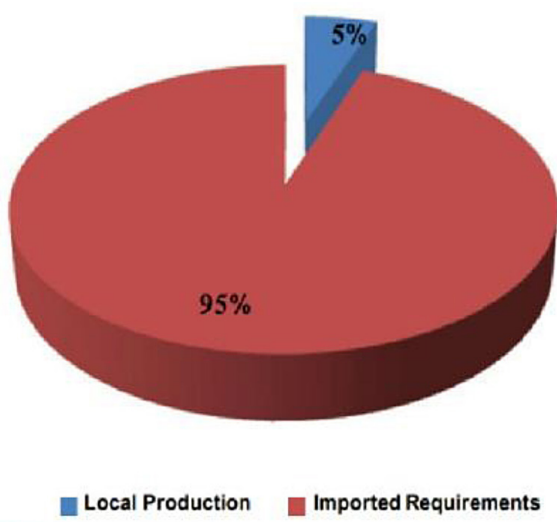

Figure 1. Pie chart of the local production share of total energy requirements 2016 in Jordan (Jordanian Ministry of Energy and Mineral Resources, 2017) 


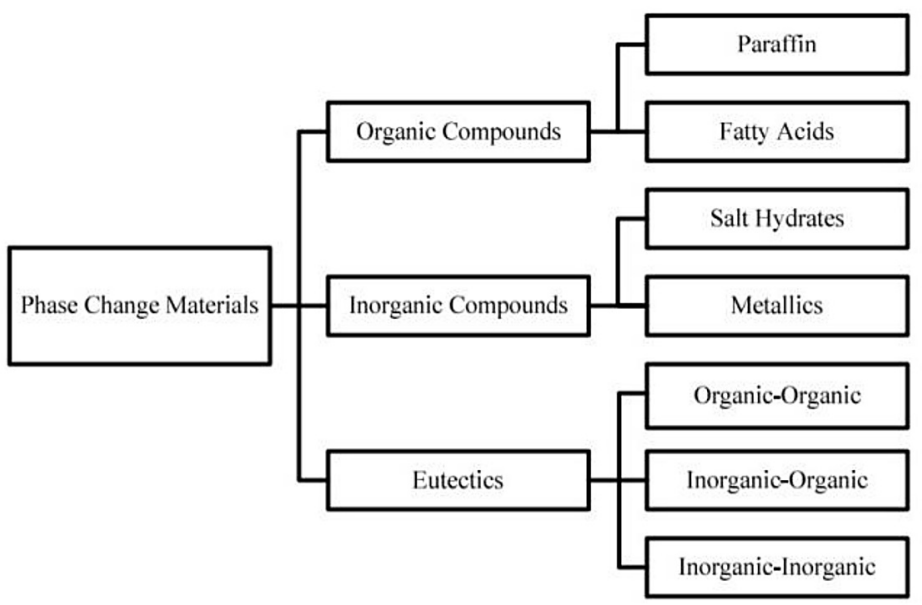

Figure 2. PCMs classification (Zhou, D., Zhao, C.Y. and Tian, Y., 2012)

PCMs can be added to cementitious systems by different means: (a) immersion into a melted liquid of PCM; or (b) impregnation by saturation or vacuum saturation with porous aggregates (Sakulich and Bentz, 2012).

According to Kadri et al., adding naphthalene sulphonate (NS) into concrete with different types of Portland cement has a great effect on the hydration peak and the compressive strength. The results of their study showed the effect of increasing the additives of NS; it accelerates the second hydration peak and also increases the compressive strength of concrete (Kadri et al., 2009).

\section{MATERIALS AND METHODS}

In this study, the mixtures of the samples were prepared with water/cement ratio of $60 \%$, and cement/ (silica sand with additives) ratio of $1: 3$, according to ASTM standards (ASTM C $192 / C$ ). The basic case reference specimens were prepared only from a mixture of water, silica sand, and cement without additives. Additives of local soil and naphthalene (Figure 3) of different proportions: $2.5 \%, 5 \%, 7 \%, 10 \%$, and $15 \%$, were added to the tested specimens. Two samples were tested; the first sample consisted of 36 small cubes with the dimensions of $3 \times 3 \times 3 \mathrm{~cm}$ and the second sample comprised 36 small $5 \times 5 \times 5 \mathrm{~cm}$ cubes. They were tested for thermal conductivity and compressive strength.

The proportions of the additives in all specimens are shown in Table 1; each prepared sample was divided into 6 groups of cubes. Each group had the same percentage of local soil and naphthalene (Table 1).
A LAB TEST 200 mixer was used in this study to mix the following components; silica sand, cement, soil, and naphthalene (Figure $4)$. The dry components were put in the mixer simultaneously, and remained in the mixer for three minutes before adding water gradually for five minutes. Afterwards, the mixture was blended well to ensure that the mixture is homogeneous and fulfills the standards. Then, the mixture was poured into the wooden molds.

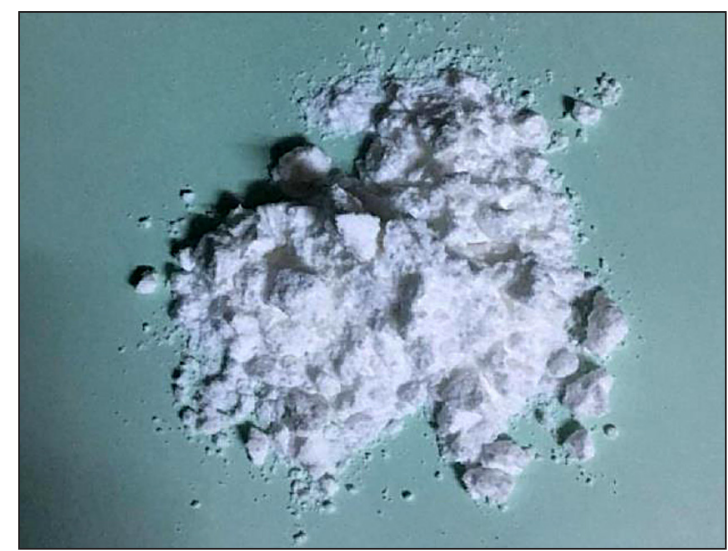

Figure 3. Naphthalene powder used in the study

Table 1. The proportions of the additives in the prepared samples

\begin{tabular}{|c|c|}
\hline Sample ID & Additives percentages (\%) \\
\hline $1-6$ & 0 \\
\hline $7-12$ & 2.5 \\
\hline $13-18$ & 5 \\
\hline $19-24$ & 7 \\
\hline $25-30$ & 10 \\
\hline $31-36$ & 15 \\
\hline
\end{tabular}




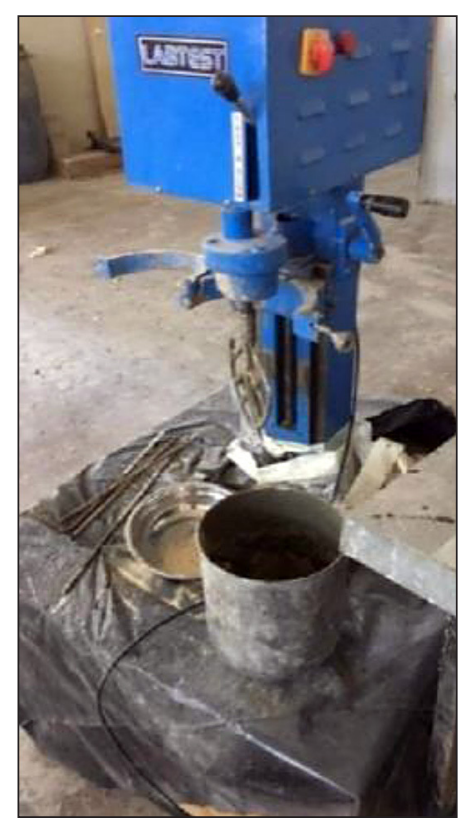

Figure 4. LAB TEST mixer

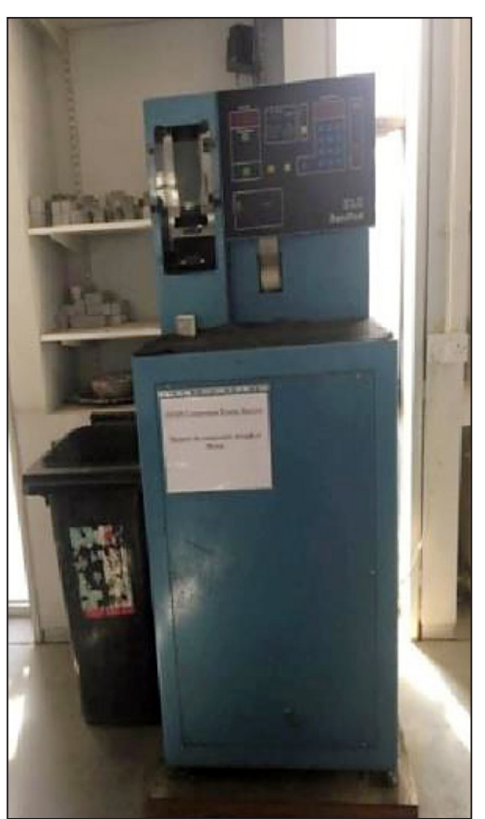

Figure 6. $250 \mathrm{kN}$ Compression Testing Machine type ELE AutoTEST

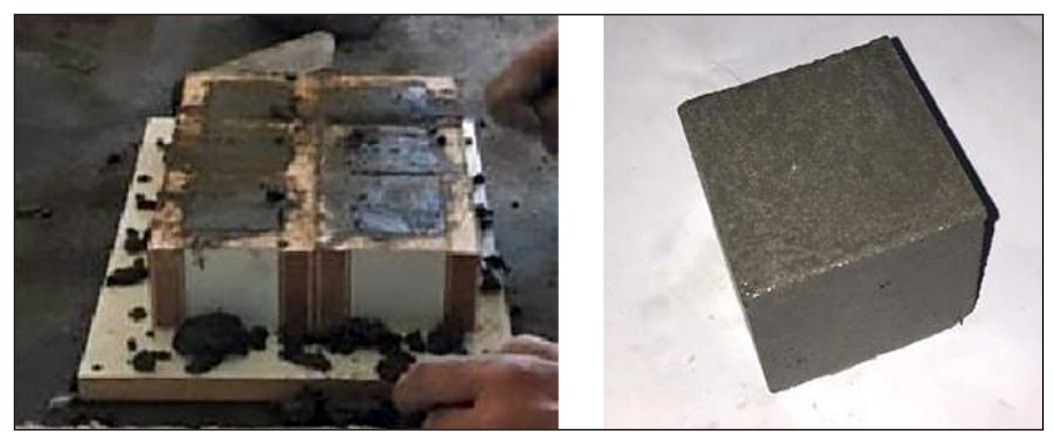

Figure 5. Molded and unmolded specimens

The used molds were cubes of $(5 \times 5 \times 5 \mathrm{~cm})$ and $(3 \times 3 \times 3 \mathrm{~cm})$. The molds were filled with the mixture in three layers; each layer was vibrated 25 times using a wooden stick $(3 \times 10 \mathrm{~cm})$. Then, the excess mixture was taken away, and the surface of the specimens was leveled with a steel trowel. The specimens were left for 24 hours before they were demolded and soaked with water for 28 days. After 28 days, the specimens were picked out of the water to be tested (Figure 5 and 6).

The samples were tested for thermal conductivity and compressive strength. The Compression Testing Machine, type ELE Auto TEST, was used to measure the compressive strength of specimens. The thermal conductivity was tested by Linear Heat Conduction Accessory-HT11C, Figure 8 and 9.

The compressive strength test was performed on the concrete specimens: 36 cubes with dimensions of $(5 \times 5 \times 5 \mathrm{~cm})$. Each six specimens have the same ratios of additives (local soil and naphthalene): $0 \%, 2.5 \%, 5 \%, 7 \%$, $10 \%$, and $15 \%$. The readings were taken from the device and the compressive strength was calculated using equation (1) and recorded in mega Pascal (MPa) (Ele.com, 2017). Figure 7 shows the failure load values resulting during the test (Ele.com, 2017).

$$
F_{c}=P / A
$$

where: $F_{c}$ - is the compressive strength of concrete $\left(\mathrm{MPa}=\mathrm{N} / \mathrm{mm}^{2}\right)$.

$P$ - measured load $(\mathrm{N})$.

$A$ - the surface area of the specimen $\left(\mathrm{mm}^{2}\right)$.

The thermal conductivity of the specimens was measured using the Armfield type: Computer Controlled Linear Heat Conduction AccessoryHT11C (Figure 8). 


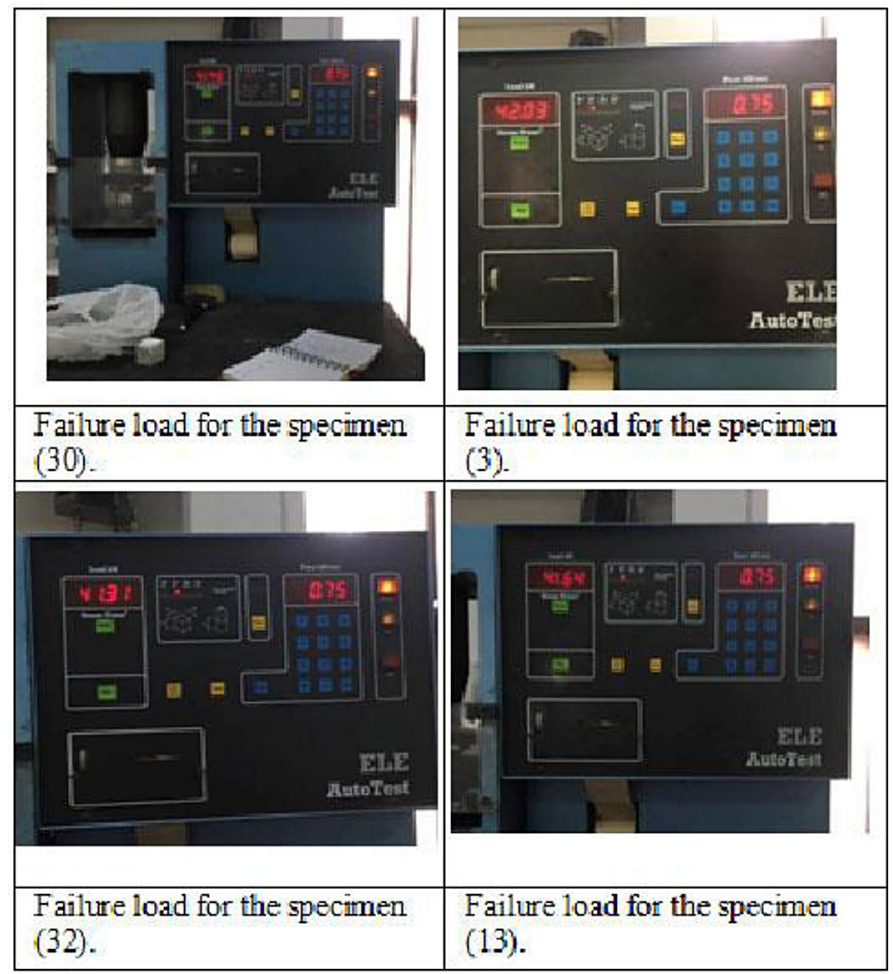

Figure 7. Failure load values resulting during the test

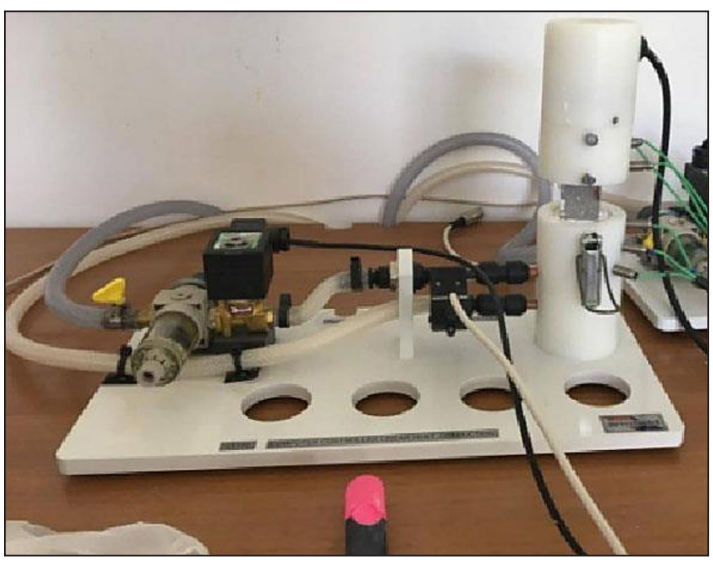

Figure 8. Armfield Linear Heat Conduction Accessory: Computer Controlled Linear Heat Conduction-HT11C

The equipment was set up as follows (Arm field, 2017):

1. All tools were connected to power sockets.

2. The linear heat Conduction Accessory- HT11C (Figure 8) was connected to the heat transfer service unit- HT10XC (Figure 9), which was connected to the computer.

3. The faces of the two sections of HT11C were isolated with thermal paste (Figure 10).

4. The concrete specimens were placed between the two sections of the HT11C (Figure 11).

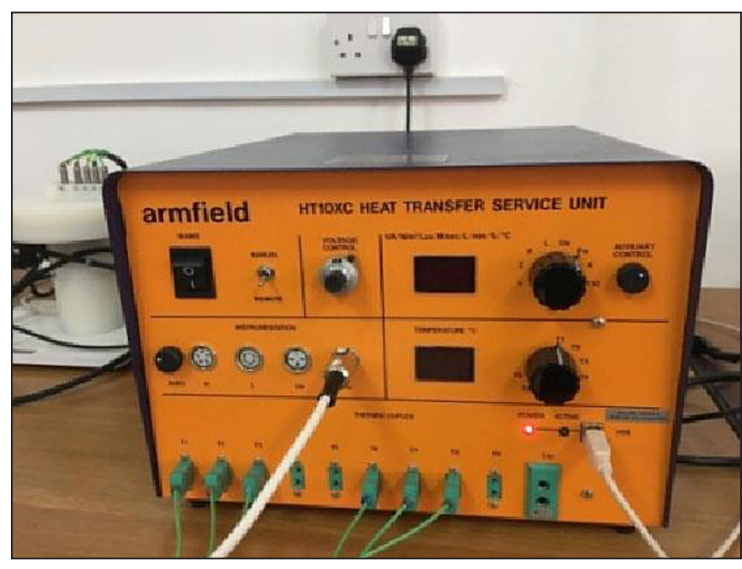

Figure 9. Heat transfer service unit-HT10XC

5. At the front of the service unit, the VOLTAGE CONTROL was adjusted to the minimum and the selector switch to the MANUAL, the cold-water flow rate sensor was linked to the cooling water flow rate socket $(\mathrm{Fw})$, and the AUXILIARY CONTROL button was adjusted to the minimum.

6. At the back of the service unit, the heater source from HT11C was linked to OUTPUT 2 socket, the valve of the cold-water flow control was linked to the AUXILIARY OUTPUT socket, and the power source from the valve of the cold-water flow control was linked to the AUXILIARY POWER socket. 


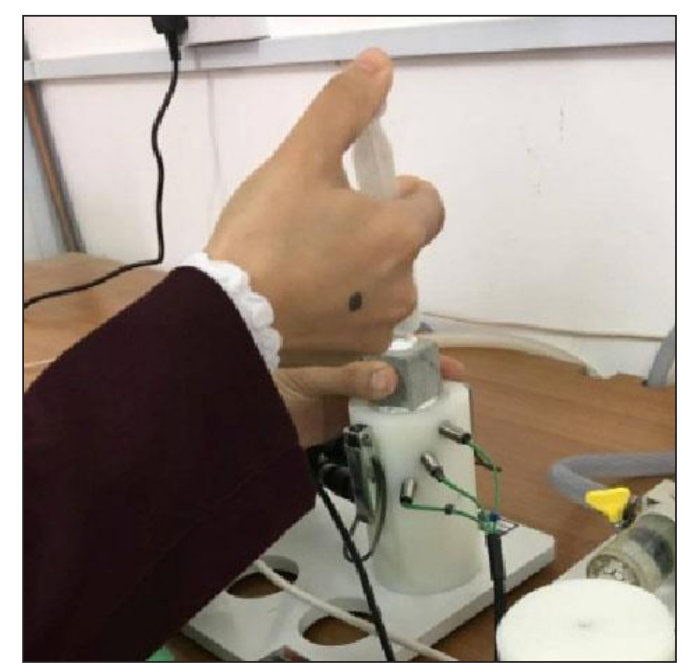

Figure 10. Thermal paste: heat sink compound

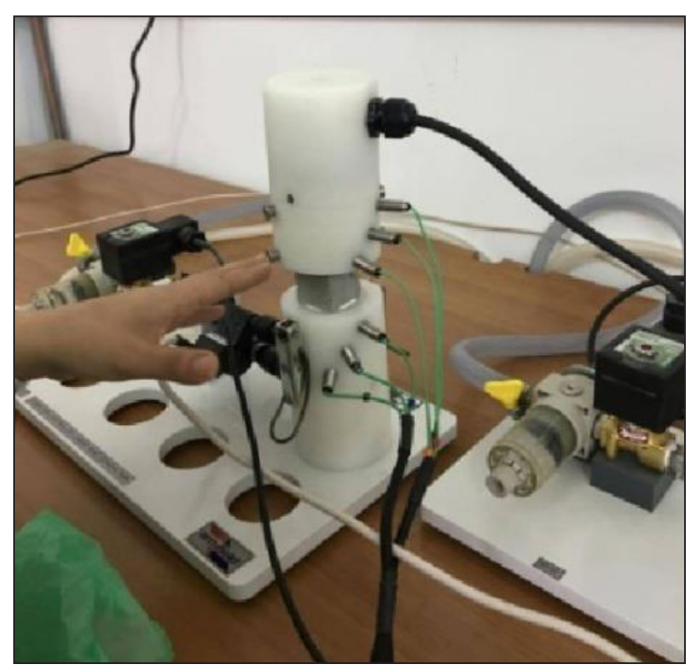

Figure 11. Placing a specimen between the two sections of the HT11C

The computer software-HT11C Linear Heat Conduction Application was used for the test; see Figure (12). The water flow-regulating valve was turned on manually; the flow control was set to 1.5 liters/min; and the heater voltage was adjusted to give 9 volts in the software mimic diagram. When the temperatures observed on the diagram became stable, the record button was pressed, and then the table window was displayed to save the following recorded values as an Excel spreadsheet (Figure 13): T1, T2, T3, T6, T7, T8, V, I, Fw (Arm field, 2017).

Knowing the amount of heat transfer between the two sides of the specimen, the $k$-value was calculated by using the following equation:

$$
k=Q \cdot \Delta x / A \cdot \Delta T\left(\mathrm{~W} / \mathrm{m}^{2} \cdot \mathrm{C}^{\circ} / \mathrm{m}\right)
$$

where: $k$ - is the thermal conductivity, $\mathrm{k}$-value $\left(\mathrm{W} / \mathrm{m}^{2} \cdot \mathrm{K} / \mathrm{m}\right)$.
$Q$ - is the heat flow rate by conduction (Watt).

$\Delta x-$ is the thickness of the specimens $(\mathrm{mm})$.

$A$ - is the cross-sectional area $\left(\mathrm{m}^{2}\right)$.

$\Delta T$ - is the temperature difference

( $T$ (hot face) $-T$ (cold face) $)$.

The temperatures of the hot face cold face were calculated using equation (3) and (4), respectively.

$$
T \text { (hots faces) }=\mathrm{T} 3-[(\mathrm{T} 2-\mathrm{T} 3) / 2]\left(\mathrm{C}^{\circ}\right)
$$

where (Rapidtables, 2017): T2 - is the heated section mid-temperature $\left(\mathrm{C}^{\circ}\right)$.

$\mathrm{T} 3$ - is the heated section low-temperature $\left(\mathrm{C}^{\circ}\right)$.

$$
T(\text { cold face })=\mathrm{T} 6+(\mathrm{T} 6-\mathrm{T} 7) / 2\left(\mathrm{C}^{\circ}\right)
$$

where: $\mathrm{T} 6-$ is the cooled section high-temperature $\left(\mathrm{C}^{\circ}\right)$.

$\mathrm{T} 7$ - is the cooled section mid-temperature $\left(\mathrm{C}^{\circ}\right)$.

Equations (5), (6), (7), and (8) were used to calculate the power, cross-section area, and temperature differences, respectively:

$$
\mathrm{Q}=\mathrm{VI} \text { (watts) }
$$

where: $\mathrm{Q}-$ is the heater power $(\mathrm{W})$.

$\mathrm{V}-$ is a heater voltage (Volts)

I - is a heater current (Amps)

Cross-sectional area:

$$
A=p\left(D^{2} / 4\right)\left(m^{2}\right)
$$

where: $\mathrm{A}-$ is the cross-sectional area $\left(\mathrm{m}^{2}\right)$.

$\mathrm{D}$ - is the diameter of section $\mathrm{D}=0.025 \mathrm{~m}$.

$$
\Delta \mathrm{T}=\mathrm{T} \text { (hot face) }-\mathrm{T} \text { (cold face) }(\mathrm{K})
$$
where: $\Delta \mathrm{T}-$ is the temperature difference $(\mathrm{K})$.

In order to convert the temperature value from Celsius $\left({ }^{\circ} \mathrm{C}\right)$ to Kelvin $(\mathrm{K})$, the equation (7) was used (Rapidtables, 2017).

$$
\mathrm{T}(\mathrm{K})=\mathrm{T}\left(\mathrm{C}^{\circ}\right)+273.15
$$

where: $\mathrm{T}\left(\mathrm{C}^{\circ}\right)$ - is a temperature in Celsius.

$\mathrm{T}(\mathrm{K})$ - is a temperature in Kelvin.

Data analyses of the results were done using Mintab 16 software.

\section{RESULTS AND DISCUSSION}

The results of this experiment indicated that there is a inversely proportional relationship between the ratio of naphthalene with local soil and 


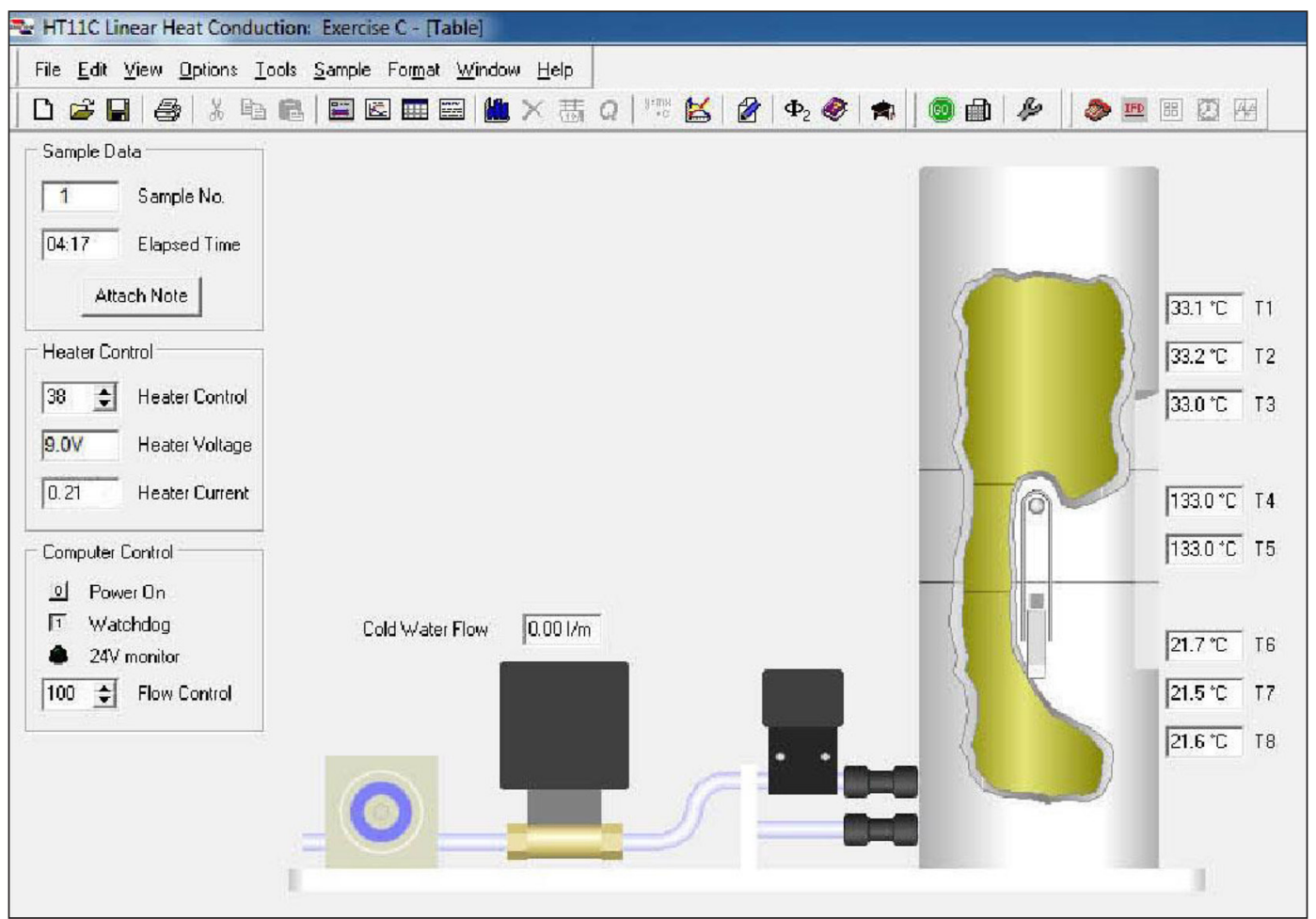

Figure 12. Software mimic diagram window-HT11C Linear Heat Conduction Application

\begin{tabular}{|c|c|c|c|c|c|c|c|c|c|c|c|c|c|c|c|c|}
\hline \multicolumn{17}{|c|}{ E. HTIC Lineser Heat Conduction Exercise C - [rable] } \\
\hline \multicolumn{17}{|c|}{ 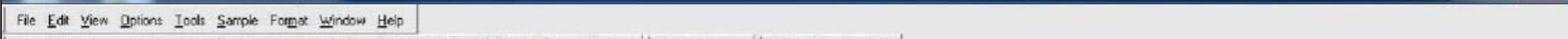 } \\
\hline 口回回 & 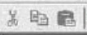 & 国国四 & 西 0 & Q & $\mid \Phi_{2} \Leftrightarrow$ & 两 6 & \& & 国國 & 3 国 & & & & & & & \\
\hline \multirow{2}{*}{ Description } & \multirow[b]{2}{*}{$\begin{array}{c}\text { Position } \\
\text { along Bar } \\
\text { [mm] }\end{array}$} & \multirow{2}{*}{$\begin{array}{c}\text { Temperature } \\
\text { Readings } \\
{\left[{ }^{\circ} \mathrm{C}\right]}\end{array}$} & \multirow{2}{*}{ 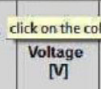 } & \multirow{2}{*}{\begin{tabular}{|l} 
olumn header: \\
$\begin{array}{c}\text { Current } \\
\text { [A] }\end{array}$
\end{tabular}} & \multirow{2}{*}{ 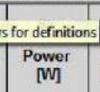 } & \multirow{2}{*}{$\begin{array}{l}\text { Water } \\
\text { Flowrate } \\
\text { [litres/min] }\end{array}$} & \multirow[b]{2}{*}{$\begin{array}{l}\text { dT hot } \\
\text { [C] }\end{array}$} & \multirow[b]{2}{*}{$\begin{array}{l}\text { dT Int } \\
{\left[{ }^{\circ} \mathrm{C}\right]}\end{array}$} & \multirow[b]{2}{*}{$\begin{array}{l}\mathrm{dT} \text { cold } \\
{\left[\mathrm{I}^{\circ} \mathrm{C}\right]}\end{array}$} & \multirow[b]{2}{*}{$\begin{array}{c}\text { Gradient } \\
\text { Hot } \\
{[\mathrm{K} / \mathrm{m}]}\end{array}$} & \multirow[b]{2}{*}{$\begin{array}{c}\text { Gradient } \\
\text { Int } \\
{\left[\begin{array}{ll}\text { K } / \mathrm{m}]\end{array}\right.}\end{array}$} & \multirow[b]{2}{*}{$\begin{array}{c}\text { Gradient } \\
\text { Cold } \\
{[\mathrm{K} / \mathrm{m}]}\end{array}$} & \multirow{2}{*}{$\begin{array}{c}\text { Extrapolated } \\
\text { Hot Temps } \\
{\left[{ }^{\circ} \mathrm{C}\right]}\end{array}$} & \multirow[b]{2}{*}{$\begin{array}{c}\text { Extrapolated } \\
\text { Int Temps } \\
{\left[{ }^{\circ} \mathrm{C}\right]}\end{array}$} & \multirow{2}{*}{$\begin{array}{c}\text { Extrapolated } \\
\text { Cold Temps } \\
{\left[{ }^{[} \mathrm{C}\right]}\end{array}$} & \multirow[b]{2}{*}{$\begin{array}{l}\text { Extrap } \\
\text { Tempe } \\
{[}\end{array}$} \\
\hline & & & & & & & & & & & & & & & & \\
\hline Thermocouple $\mathrm{T} 1$ & 15.0 & 47.6 & 9.0 & 0.78 & & 1.50 & -19 & -22.5 & .0 .2 & 64.941 & .747097 & -6.494 & 47.6 & & & 47 \\
\hline Thermocouple I2 & 30.0 & 46.6 & & & & & & & & & & & 46.6 & & & 4t \\
\hline Thermocouple I3 & 45.0 & 45.7 & & & & & & & & & & & 45.7 & & & 45 \\
\hline Hot Face & 52.5 & & & & & & & & & & & & 45.2 & 45.2 & & 4t \\
\hline Intermediate 1 & 60.0 & & & & & & & & & & & & & 39.6 & & 35 \\
\hline Intermediate 2 & 75.0 & & & & & & & & & & & & & 27.4 & & $2 x$ \\
\hline Cold Face & 825 & & & & & & & & & & & & & & 227 & z: \\
\hline Themocouple T6 & 900 & 227 & & & & & & & & & & & & & 227 & 2 \\
\hline Thermocouple I7 & 105.0 & 22.4 & & & & & & & & & & & & & 22.4 & $z$ \\
\hline Thermocouple TB & 1200 & 225 & & & & & & & & & & & & & 22.5 & 2 \\
\hline
\end{tabular}

Figure 13. Software sheet window-HT11C Linear Heat Conduction Application

the thermal conductivity of concrete. The average of k-values of modified concrete specimens (sample1) varied between $0.55\left(\mathrm{~W} / \mathrm{m}^{2} . \mathrm{K} / \mathrm{m}\right)$ to 0.49 $\left(\mathrm{W} / \mathrm{m}^{2} \cdot \mathrm{K} / \mathrm{m}\right)$. This result is reduced compared with the reference case value, which is $0.57(\mathrm{~W} /$ $\left.\mathrm{m}^{2} . \mathrm{K} / \mathrm{m}\right)$. This reduction is about $(95.79-85.91) \%$ of the thermal conductivity in the reference specimens which are made from regular concrete. Additionally, the average k-values of modified concrete in sample 2 varied between $0.83(\mathrm{~W} /$ $\left.\mathrm{m}^{2} . \mathrm{K} / \mathrm{m}\right)$ to $0.73\left(\mathrm{~W} / \mathrm{m}^{2} . \mathrm{K} / \mathrm{m}\right)$, compared with $0.86\left(\mathrm{~W} / \mathrm{m}^{2} . \mathrm{K} / \mathrm{m}\right)$ of the second reference specimens. This reduction is about $(96.35 \%-84.67 \%)$ of the thermal conductivity in the reference specimens (Table 2).
Statistically, Figure 14 indicates that the reference specimens have the highest means of $\mathrm{K}$ value which are $0.57,0.87\left(\mathrm{~W} / \mathrm{m}^{2} . \mathrm{K} / \mathrm{m}\right)$ for sample1 and sample2, respectively. Followed by the specimens incorporated of the ratio $2.5 \%$ of additives, which have the $\mathrm{K}$-value means of $0.55,0.83$ $\left(\mathrm{W} / \mathrm{m}^{2} \mathrm{~K} / \mathrm{m}\right)$. The means of $\mathrm{K}$-value, for the specimens with additive ratio of $5 \%$, are $0.54,0.81(\mathrm{~W} /$ $\mathrm{m}^{2} . \mathrm{K} / \mathrm{m}$ ) for sample1 and sample2, respectively. The means of k-value, for the specimens with additives of ratio $7 \%$, are $0.52,0.79\left(\mathrm{~W} / \mathrm{m}^{2} . \mathrm{K} / \mathrm{m}\right)$ for sample1 and sample2, respectively. The largest reduction in heat transfer coefficient was for additives ratios of $10 \%$ and $15 \%$. The means of K-value, for the specimens of the ratio $10 \%$, are 0.51 , 
Table 2. Thermal conductivity of the modified concrete specimens

\begin{tabular}{|c|c|c|c|c|c|c|c|}
\hline ID & $\begin{array}{c}\text { Additives } \\
(\%)\end{array}$ & $\begin{array}{c}\text { K-value } \\
\left(\mathrm{W} / \mathrm{m}^{2} . \mathrm{K} / \mathrm{m}\right) \\
\text { Sample } 1\end{array}$ & $\begin{array}{c}\text { K-value Average } \\
\left(\mathrm{W} / \mathrm{m}^{2} . \mathrm{K} / \mathrm{m}\right) \\
\text { Sample } 1\end{array}$ & $\begin{array}{c}\text { Reduction of } \\
\text { K-value (\%) } \\
\text { Sample } 1\end{array}$ & $\begin{array}{c}\text { K-value }(\mathrm{W} / \\
\left.\mathrm{m}^{2} . \mathrm{K} / \mathrm{m}\right) \\
\text { Sample } 2\end{array}$ & $\begin{array}{c}\text { K-value Average } \\
\left(\mathrm{W} / \mathrm{m}^{2} . \mathrm{K} / \mathrm{m}\right) \\
\text { Sample } 2\end{array}$ & $\begin{array}{c}\text { Reduction of } \\
\text { K-value (\%) } \\
\text { Sample } 2\end{array}$ \\
\hline 1 & 0 & 0.57 & \multirow{6}{*}{0.57} & \multirow{6}{*}{100,0} & 0.87 & \multirow{6}{*}{0.86} & \multirow{6}{*}{100,0} \\
\hline 2 & 0 & 0.57 & & & 0.87 & & \\
\hline 3 & 0 & 0.57 & & & 0.86 & & \\
\hline 4 & 0 & 0.57 & & & 0.86 & & \\
\hline 5 & 0 & 0.57 & & & 0.87 & & \\
\hline 6 & 0 & 0.57 & & & 0.86 & & \\
\hline 7 & 2.5 & 0.55 & \multirow{6}{*}{0.55} & \multirow{6}{*}{95.79} & 0.84 & \multirow{6}{*}{0.83} & \multirow{6}{*}{96.35} \\
\hline 8 & 2.5 & 0.55 & & & 0.84 & & \\
\hline 9 & 2.5 & 0.55 & & & 0.83 & & \\
\hline 10 & 2.5 & 0.55 & & & 0.83 & & \\
\hline 11 & 2.5 & 0.55 & & & 0.83 & & \\
\hline 12 & 2.5 & 0.55 & & & 0.83 & & \\
\hline 13 & 5 & 0.54 & \multirow{6}{*}{0.54} & \multirow{6}{*}{93.79} & 0.82 & \multirow{6}{*}{0.81} & \multirow{6}{*}{94.14} \\
\hline 14 & 5 & 0.54 & & & 0.82 & & \\
\hline 15 & 5 & 0.54 & & & 0.81 & & \\
\hline 16 & 5 & 0.54 & & & 0.81 & & \\
\hline 17 & 5 & 0.54 & & & 0.81 & & \\
\hline 18 & 5 & 0.53 & & & 0.81 & & \\
\hline 19 & 7 & 0.53 & \multirow{6}{*}{0.52} & \multirow{6}{*}{91.22} & 0.79 & \multirow{6}{*}{0.79} & \multirow{6}{*}{90.89} \\
\hline 20 & 7 & 0.53 & & & 0.79 & & \\
\hline 21 & 7 & 0.52 & & & 0.79 & & \\
\hline 22 & 7 & 0.52 & & & 0.79 & & \\
\hline 23 & 7 & 0.52 & & & 0.78 & & \\
\hline 24 & 7 & 0.52 & & & 0.79 & & \\
\hline 25 & 10 & 0.51 & \multirow{6}{*}{0.51} & \multirow{6}{*}{88.97} & 0.76 & \multirow{6}{*}{0.76} & \multirow{6}{*}{87.98} \\
\hline 26 & 10 & 0.51 & & & 0.77 & & \\
\hline 27 & 10 & 0.51 & & & 0.77 & & \\
\hline 28 & 10 & 0.51 & & & 0.76 & & \\
\hline 29 & 10 & 0.51 & & & 0.75 & & \\
\hline 30 & 10 & 0.51 & & & 0.76 & & \\
\hline 31 & 15 & 0.49 & \multirow{6}{*}{0.49} & \multirow{6}{*}{85.91} & 0.74 & \multirow{6}{*}{0.73} & \multirow{6}{*}{84.67} \\
\hline 32 & 15 & 0.49 & & & 0.73 & & \\
\hline 33 & 15 & 0.49 & & & 0.73 & & \\
\hline 34 & 15 & 0.49 & & & 0.73 & & \\
\hline 35 & 15 & 0.49 & & & 0.73 & & \\
\hline 36 & 15 & 0.49 & & & 0.73 & & \\
\hline
\end{tabular}

$0.76\left(\mathrm{~W} / \mathrm{m}^{2} . \mathrm{K} / \mathrm{m}\right)$ and the means of K-values, for the specimens incorporated of the ratio $15 \%$, are $0.49,0.73\left(\mathrm{~W} / \mathrm{m}^{2} . \mathrm{K} / \mathrm{m}\right)$ for sample1 and sample2, respectively. It is apparent that the heat loss is inversely proportional to the ratios of additives to the cement. A higher percentage of naphthalene in the cement mixture definitely means lesser heat transfer coefficient factor (k-value).
This reduction in the heat transfer coefficient (k-value) will significantly reflect the heating or cooling loads in buildings and eventually will reduce the overall energy consumption in buildings.

However, the percentage of additives should be controlled and a compromise with the compressive stress of concrete should be reached. The cement cubes in the samples were tested in terms 
of compressive strength. Figure 15 indicates that the compressive strength and the thermal conductivity are correlated with additives ratios. It is possible to predict the thermal conductivity and compressive strength values using the additive ratio. The smoother lines, in Figure 16, show a curvilinear relationship between the thermal conductivity and the compressive strength.

In Figure 17, the darker regions indicate higher K-values. The highest K-values are located in the lower left corner on the graph, indicating that when the thickness and additive ratio decrease, the thermal conductivity increases. On the other hand, the light green areas of the graph indicate that lower K-values occur with a high percentage of additives and large thickness. The lowest Kvalues are located in the upper right corner of the graph, indicating that when thickness increases and additive ratio increases, the thermal conductivity decreases.

The compressive strength data were analyzed using the famous statistical test (Anderson-Darling test). Figures 18, 19, and 20 show the normal probabilities of the thermal conductivity and the compressive strength values. The compressive strength and thermal conductivity data deviate from the fitted line most clearly in distribution tails. The P-value, for the thermal conductivity, shows that the data do not keep track of a regular distribution at levels greater than 0.039 and 0.169 for sample1 and sample2, respectively. These data have a small tendency, at the lower part of a test line, to be less, and to be more than the regular distribution, at the upper part of the line.

The p-value, for the compressive strength, shows that the data do not keep track of the

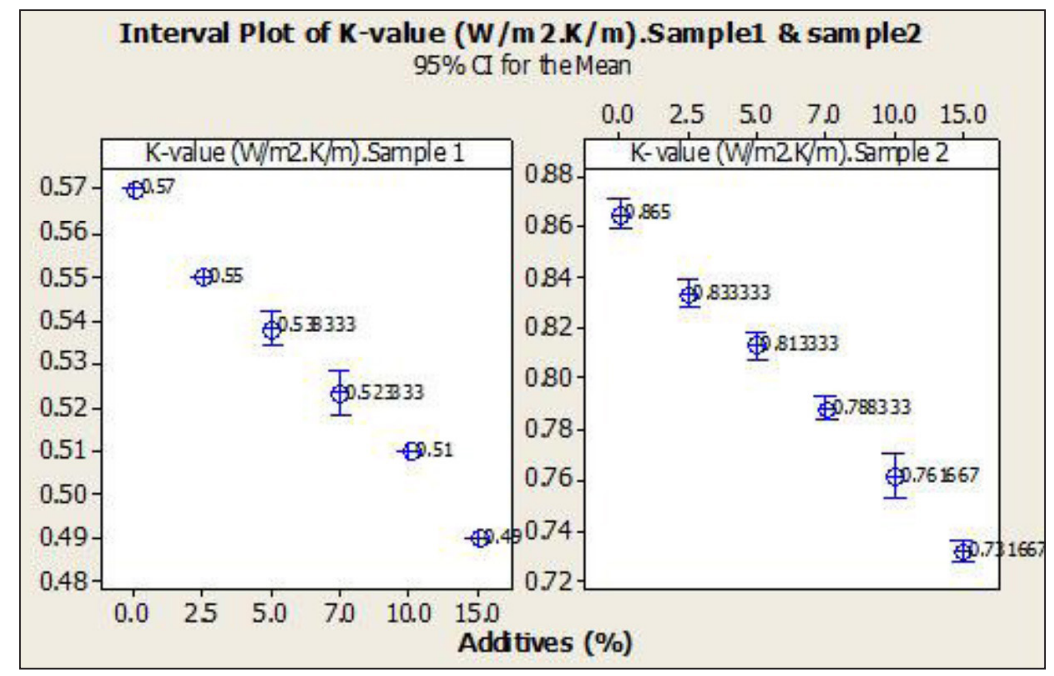

Figure 14. Interval plot of thermal conductivity $\left(\mathrm{W} / \mathrm{m}^{2} \cdot \mathrm{K} / \mathrm{m}\right)$

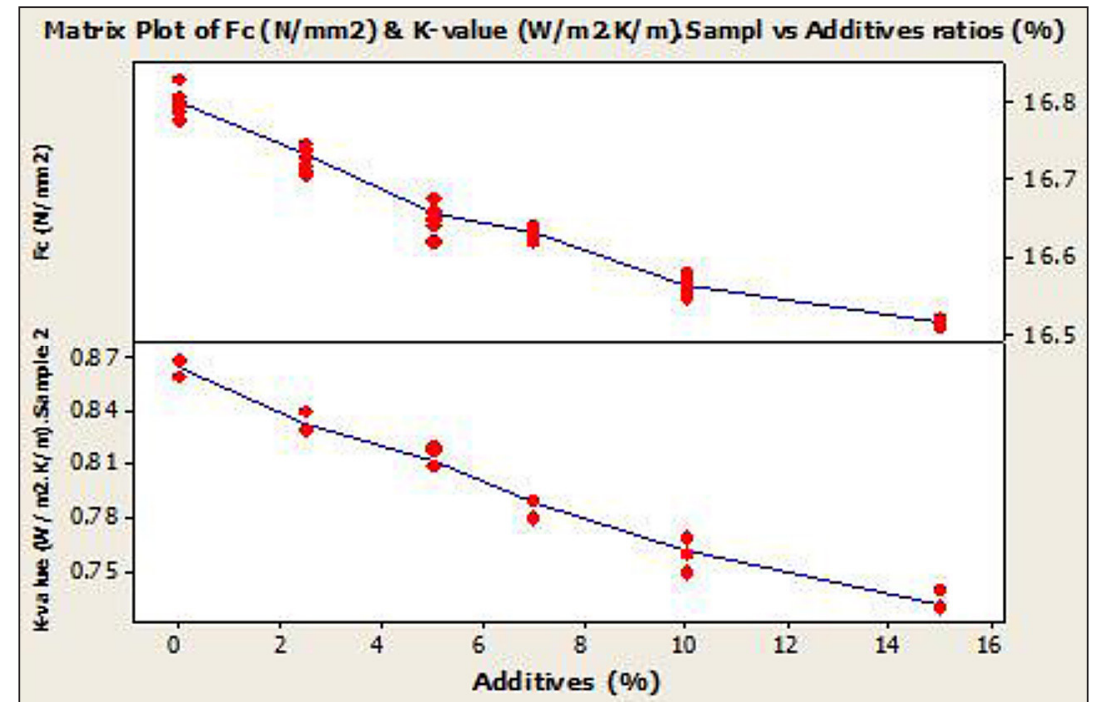

Figure 15. Matrix plot of thermal conductivity and compressive strength $\left(\mathrm{N} / \mathrm{mm}^{2}\right)$ vs. additives ratios $(\%)$ 


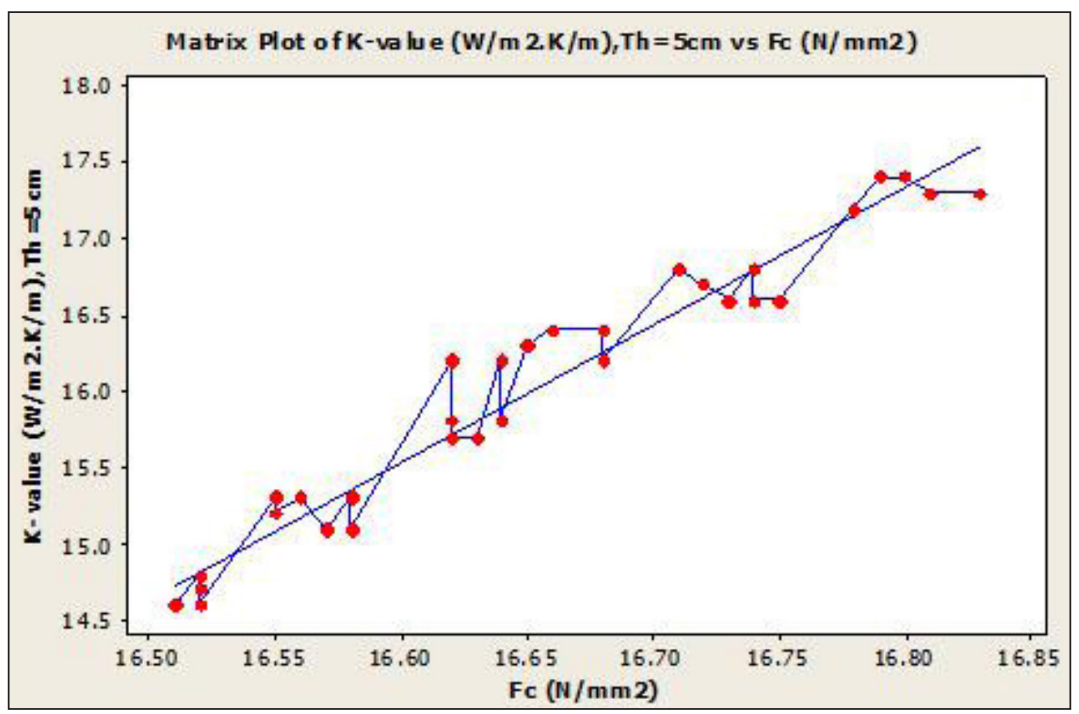

Figure 16. Matrix plot of thermal conductivity $\left(\mathrm{W} / \mathrm{m}^{2} . \mathrm{K} / \mathrm{m}\right)$ vs. compressive strength $\left(\mathrm{N} / \mathrm{mm}^{2}\right)$, Sample2

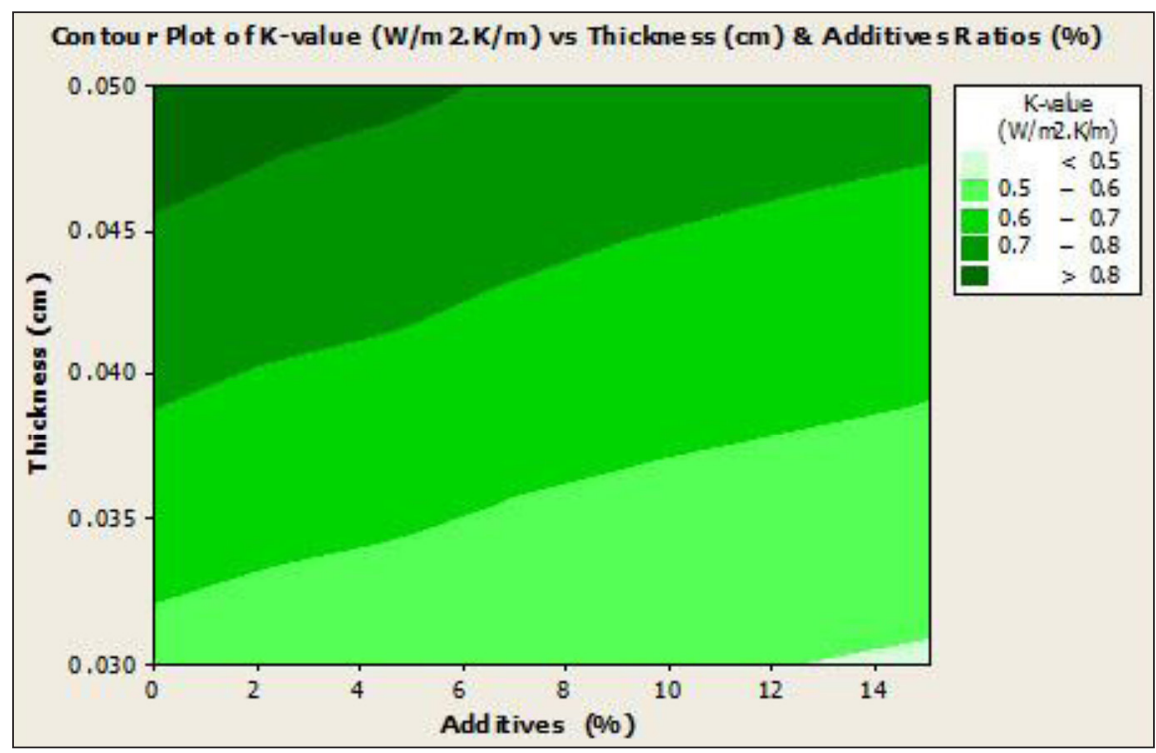

Figure 17. The thermal conductivity $\left(\mathrm{W} / \mathrm{m}^{2} . \mathrm{K} / \mathrm{m}\right)$ vs. thickness $(\mathrm{cm})$ and additives ratios $(\%)$

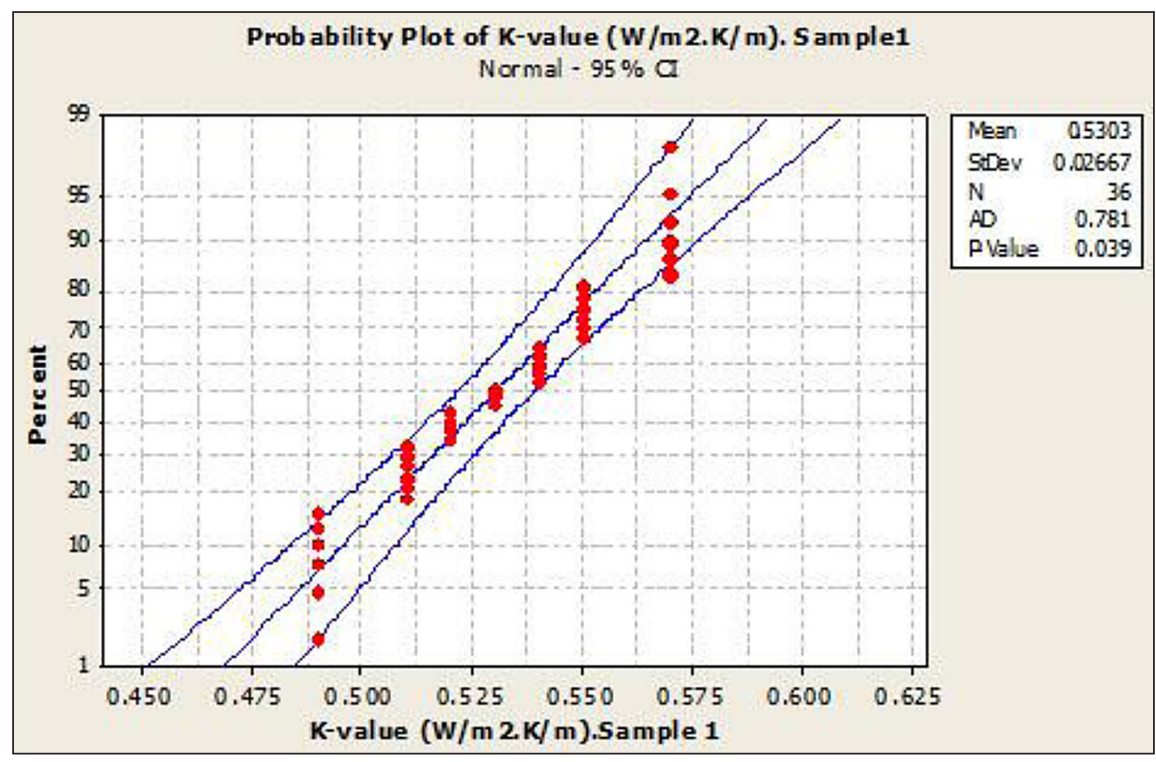

Figure 18. Probability plot of thermal conductivity $\left(\mathrm{W} / \mathrm{m}^{2} . \mathrm{K} / \mathrm{m}\right)$, Sample1 


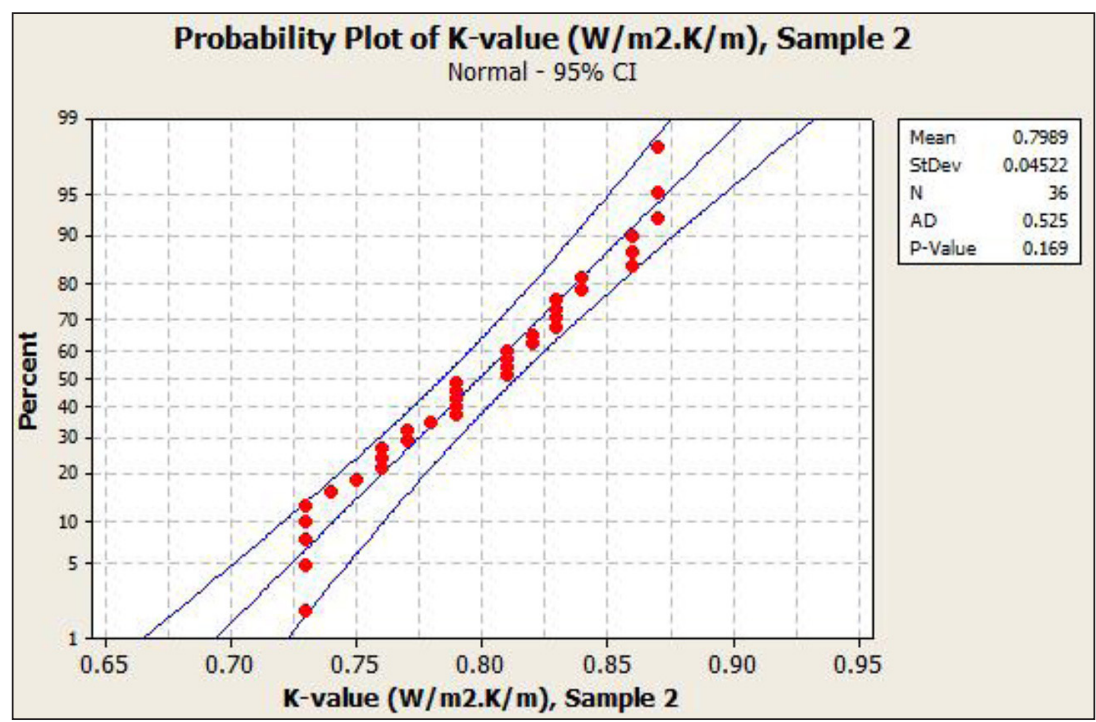

Figure 19. Probability plot of thermal conductivity $\left(\mathrm{W} / \mathrm{m}^{2} . \mathrm{K} / \mathrm{m}\right)$, Sample2

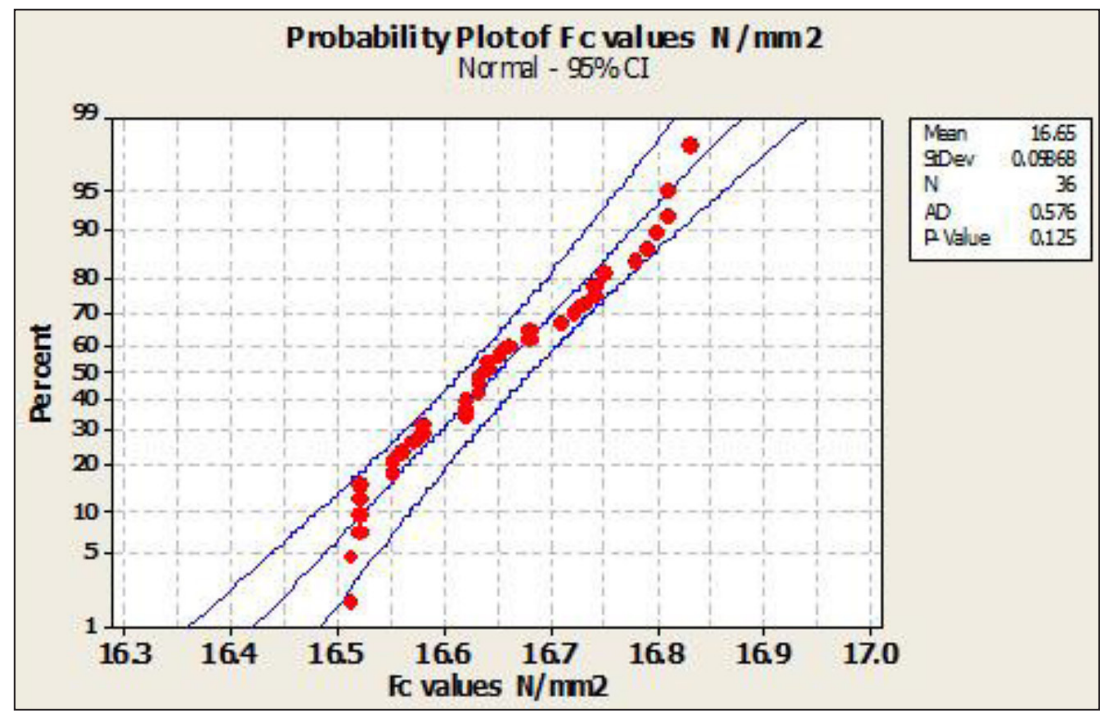

Figure 20. Probability plot of compressive strength $\left(\mathrm{N} / \mathrm{mm}^{2}\right)$

regular distribution at levels greater than 0.125 . In addition, these data have a small tendency to be lesser, at the lower part of the test line, and to be greater than the regular distribution, at the upper part of the line. Accordingly, the compressive strength of the tested specimens is apparently reduced and kept within the acceptable range. Most of the tested cubes show little reduction in the regular compressive strength; mainly about $98.33 \%$ from the reference case (Table 3 ).

\section{CONCLUSIONS}

This study indicates that naphthalene and soil could be used to enhance the thermal conductivity of concrete. Apparently, adding naphthalene to the concrete mixture leads to a great reduction in heat transfer coefficient which eventually contributes positively to minimizing the energy consumption in buildings. As the ratio of these additives plays a big role in determining the k-value, designers should consider the effect of this added material on the compressive strength. In order to achieve the optimal ratio of the additives, the compressive strength was considered in all tests of the specimens. The optimal ratio of the additives is the ratio that gives the highest decrease in the thermal conductivity with a compressive strength value within the acceptable range.

Incorporation of naphthalene and soil into concrete provides a promising method in the passive design field. Building users will be more comfortable with the quality of the indoor environment. 
Table 3. Compressive strength of the modified concrete specimens

\begin{tabular}{|c|c|c|c|c|c|c|c|c|c|}
\hline ID & $\begin{array}{c}\text { Additives } \\
(\%)\end{array}$ & $\begin{array}{c}\mathrm{Fc} \\
\left(\mathrm{N} / \mathrm{mm}^{2}\right) \\
\end{array}$ & $\begin{array}{c}\text { Fc Average } \\
\left(\mathrm{N} / \mathrm{mm}^{2}\right)\end{array}$ & $\begin{array}{c}\text { Reduction of } \\
\text { Fc (\%) }\end{array}$ & ID & $\begin{array}{c}\text { Additives } \\
(\%)\end{array}$ & $\begin{array}{c}F c \\
\left(\mathrm{~N} / \mathrm{mm}^{2}\right) \\
\end{array}$ & $\begin{array}{c}\text { Fc Average } \\
\left(\mathrm{N} / \mathrm{mm}^{2}\right)\end{array}$ & $\begin{array}{c}\text { Reduction of } \\
\text { Fc (\%) }\end{array}$ \\
\hline 1 & 0 & 16.80 & \multirow{6}{*}{16.80} & \multirow{6}{*}{100,0} & 19 & 7 & 16.64 & \multirow{6}{*}{16.63} & \multirow{6}{*}{98.99} \\
\hline 2 & 0 & 16.79 & & & 20 & 7 & 16.62 & & \\
\hline 3 & 0 & 16.81 & & & 21 & 7 & 16.63 & & \\
\hline 4 & 0 & 16.83 & & & 22 & 7 & 16.63 & & \\
\hline 5 & 0 & 16.81 & & & 23 & 7 & 16.63 & & \\
\hline 6 & 0 & 16.78 & & & 24 & 7 & 16.62 & & \\
\hline 7 & 2.5 & 16.74 & \multirow{6}{*}{16.73} & \multirow{6}{*}{99.58} & 25 & 10 & 16.55 & \multirow{6}{*}{16.57} & \multirow{6}{*}{98.63} \\
\hline 8 & 2.5 & 16.71 & & & 26 & 10 & 16.56 & & \\
\hline 9 & 2.5 & 16.72 & & & 27 & 10 & 16.58 & & \\
\hline 10 & 2.5 & 16.74 & & & 28 & 10 & 16.55 & & \\
\hline 11 & 2.5 & 16.75 & & & 29 & 10 & 16.57 & & \\
\hline 12 & 2.5 & 16.73 & & & 30 & 10 & 16.58 & & \\
\hline 13 & 5 & 16.66 & \multirow{6}{*}{16.66} & \multirow{6}{*}{99.17} & 31 & 15 & 16.52 & \multirow{6}{*}{16.52} & \multirow{6}{*}{98.33} \\
\hline 14 & 5 & 16.68 & & & 32 & 15 & 16.52 & & \\
\hline 15 & 5 & 16.65 & & & 33 & 15 & 16.51 & & \\
\hline 16 & 5 & 16.64 & & & 34 & 15 & 16.52 & & \\
\hline 17 & 5 & 16.68 & & & 35 & 15 & 16.51 & & \\
\hline 18 & 5 & 16.62 & & & 36 & 15 & 16.52 & & \\
\hline
\end{tabular}

This enhancement will make the annual heating costs much lower than the current costs, through developing a sustainable design to achieve a good level of energy savings. This study can contribute to achieving environmental benefits by reducing the woods and fuel combustion practices for heating in Jordan. Therefore, this study contributes positively to enhancing the safety measures for the population from the pollution footprint and its negative impact on public health.

This experimental study shows that the compressive strength values of concrete, incorporated with naphthalene and soil, are lower than the concrete without the additives. This is attributed to the following: (a) the chemical reaction between the additives and hydration components; (b) the decrease of the hydration heat, which develops the earlier strength; and (c) the changes in the porous structure. Thus, it is necessary to investigate the incorporation of naphthalene and soil into concrete by encapsulation technique. In addition, this study shows that the thickness of concrete specimens has a significant role to reduce the thermal conductivity; thus, the concrete wall thickness must be modified for greater efficiency. This enhancement in the thermal properties of concrete can be applied in the building systems as concrete block used in curtain walls but not as structural elements.

\section{Acknowledgements}

The authors would like to thank the department of architecture at JUST University for facilitating the work on this research. Special thanks also go to the staff at Civil Engineering for the great assistantship in testing the samples. Not to forget the staff at Renewable and Sustainable Energy Engineering Department/ Al al-Bayt University for all their technical assistance.

\section{REFERENCES}

1. Alva, G., Liu, L., Huang, X. and Fang, G., 2017. Thermal energy storage materials and systems for solar energy applications. Renewable and Sustainable Energy Reviews, 68, 693-706.

2. American Society for Testing and Materials, ASTM C 192/C 192M - 06. Standard Practice for Making and Curing Concrete Test Specimens in the Laboratory.

3. Armfieldonline.com. (2017). Armfield - Engineering Teaching Equipment and Industrial Food and Beverage R\&D Equipment. [online] Available at: http://armfieldonline.com/en [Accessed 4 Dec. 2017].

4. Ele.com. (2017). ELE International - ADR-Auto V2.0 2000 Standard Compression Machine. [online] Available at: http://www.ele.com/Product/2- 
adr-auto-v2-0-2000-standard-compression-machine/92 [Accessed 15 May 2017].

5. Jordanian Ministry of Energy and Mineral Resources. (2017). Energy 2017 - Facts \& Figures. [online] Available at: http://www.memr.gov.jo/ EchoBusV3.0/SystemAssets/PDFs/EN/Bruchure\%202017.pdf [Accessed 5 May 2017].

6. Kadri, E.H., Aggoun, S. and De Schutter, G., 2009. Interaction between C $3 \mathrm{~A}$, silica fume and naphthalene sulphonate superplasticiser in high performance concrete. Construction and Building Materials, 23(10), 3124-3128.

7. Rapidtables.com. (2017). How to convert Celsius to Kelvin (K). [online] Available at: http://www. rapidtables.com/convert/temperature/how-celsius- to-kelvin.htm [Accessed 15 May 2017].

8. Sakulich, A.R. and Bentz, D.P., 2012. Incorporation of phase change materials in cementitious systems via fine lightweight aggregate. Construction and Building Materials, 35, 483-490.

9. Shariah, A., Tashtoush, B. and Rousan, A. (1997). Cooling and heating loads in residential buildings in Jordan. Energy and Buildings, 26(2), 137-143.

10. Sharma, B., 2013. Incorporation of Phase Change Materials into Cementitious Systems (Doctoral dissertation, Arizona State University).

11. Zhou, D., Zhao, C.Y. and Tian, Y., 2012. Review on thermal energy storage with phase change materials (PCMs) in building applications. Applied energy, 92, 593-605. 